Article

\title{
Model-Based Design and Process Optimization of Continuous Single Pass Tangential Flow Filtration Focusing on Continuous Bioprocessing
}

\author{
Maximilian J. Huter and Jochen Strube * \\ Institute for Separation and Process Technology, Clausthal University of Technology, 38678 Clausthal-Zellerfeld, \\ Germany; Huter@itv.tu-clausthal.de \\ * Correspondence: strube@itv.tu-clausthal.de
}

Received: 2 April 2019; Accepted: 8 May 2019; Published: 28 May 2019

check for updates

\begin{abstract}
In this study the Single-Pass-Tangential-Flow-Filtration (SPTFF) concept for continuous ultrafiltration in bioprocessing is investigated. Based on a previously validated physico-chemical model for a single ultrafiltration cassette, the transfer to a multistage SPTFF is predicted and validated experimentally by concentration steps for bovine serum albumin (BSA) and the monoclonal antibody immunoglobulin $\mathrm{G}(\mathrm{IgG})$ are compared. The model applied for the ultrafiltration membrane contains the Stagnant Film Model (SFM) for concentration polarization, as well as the Osmotic Pressure Model (OPM) and the Boundary Layer Model (BLM) for the mass transfer through the membrane. In addition, pressure drop correlations as a function of the Reynolds number are included to describe the development of the transmembrane pressure over the length of the module. The outcome of this study shows the potential to improve this multi-parameter dependent unit operation by a model-based optimization allowing significant reduction of experimental efforts and applying the Quality by Design $(\mathrm{QbD})$ approach consistently. Consequently, a versatile tool for conceptual process design is presented and further application is discussed.
\end{abstract}

Keywords: ultrafiltration; Single-Pass-Tangential-Flow-Filtration (SPTFF), modelling; Continuous Bioprocessing (CBP), Conceptual Process Design (CPD)

\section{Introduction}

For the biotechnological and pharmaceutical industry membrane-based unit operations are key process steps in order to adjust the concentration of the target component and the buffer media composition. This is mainly based on their mild temperature and process conditions and the low operation costs [1-11]. A high concentration of target protein leads to improved operating conditions for the following separation steps, e.g., chromatography, and lowers their operation costs.

Due to the high concentrations of the target molecules in the range of tens to hundreds of grams per liter, the solution becomes highly viscous and reaches values up to of $80 \mathrm{mPa} \cdot \mathrm{s}$ [12]. This leads to a significant pressure drop, which may exceed the pressure limit of the ultrafiltration systems and results in a higher operation cost expenditure (OPEX). By adjustment of the $\mathrm{pH}$ value or by adding excipients, the fluid properties are modifiable [13,14], but a risk for precipitation remains [15]. Another way to handle these highly concentrated solutions is by altering the geometries of the membrane channels.

The downstream processing (DSP) of biopharmaceuticals like monoclonal antibodies creates the major share of manufacturing costs $(50-80 \%)[16,17]$. For this reason, DSP provides a great potential to optimize the economics of manufacturing. Continuous bioprocessing (CBP) is one approach to reduce production costs by increasing the production capacity [18]. Furthermore, it increases the product quality as recent publications [19-22] have already mentioned. Due to negative experiences 
during clinical trials, the FDA demands innovations in the fields of Quality by Design (QbD) and Process Analytical Technology (PAT) for pharmaceutical manufacturing [23-27]. Switching from batch to continuous processes is a promising possibility to overcome critical operation problems (e.g., batch failures, quality variations), but to create an attractive alternative to traditional batch or disposable concepts, the continuous process must be optimized at first. One of the major contributions must come from substantially lowering overall Cost of Goods (CoG) [28,29].

While for many separation steps continuous options are already established (e.g., chromatography [30] or liquid-liquid-extraction [31,32]), ultrafiltration and diafiltration just came to market recently, although they are key units in every downstream process [2,3,33]. Figure 1 shows exemplary concepts for continuous ultrafiltration based on literature [33,34].

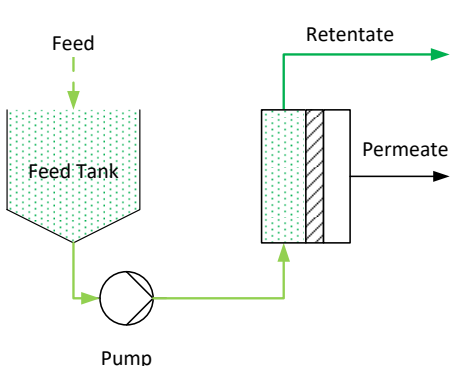

(a)

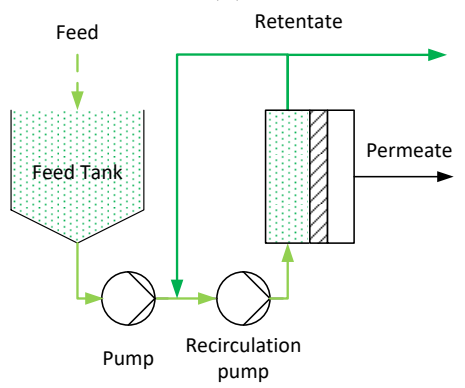

(c)

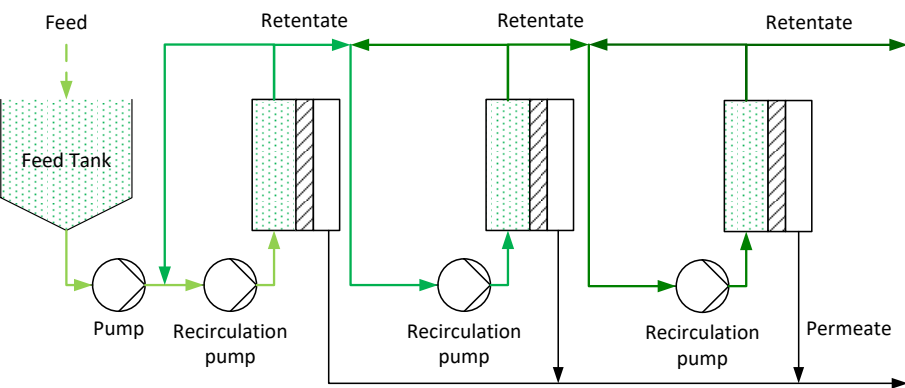

(b)

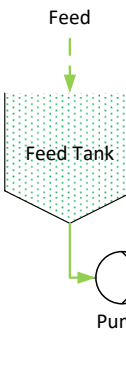

Retentate

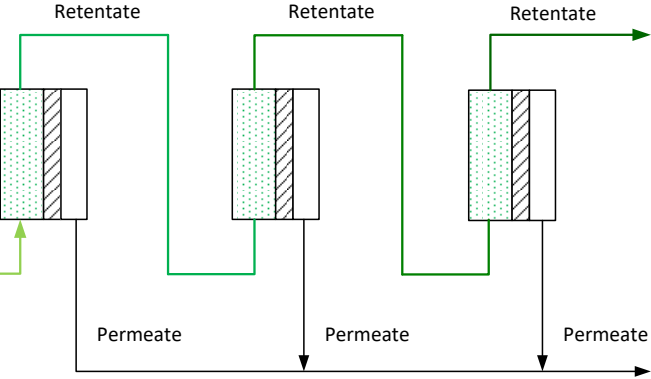

(d)

Figure 1. Concepts in literature for ultrafiltration (a) Feed and Bleed (b) Multistep Feed and Bleed (c) Single Pass Tangential Flow (SPTFF) (d) Multistep SPTFF [33,34].

Some continuous concepts contain recycling loops like the "Feed and Bleed" concept (see Figure 1a) [34]. These recycling loops increase the overall permeate stream, resulting in high residence times and several pump-passes of the target molecule. Compared to this Single-Pass-Tangential-Flow-Filtration (SPTFF) just has one pump pass and no recirculation, which could reduce potential issues like aggregation or denaturation [22]. This makes SPTFF the reasonable continuous filtration for biopharmaceuticals. Because of the low permeate volume, it is essential to increase the membrane area for SPTFF to reach high concentration factors. In addition, the concentration no longer depends on the time, like in several batch filtrations, but changes depending on the filtration path length. To achieve this, multistage filtration units (see Figure 1d) are necessary to overcome this limitation and it gets possible to reach concentration factors from $2 \times$ to $5 \times$ in a four-in-series module [35]. Additionally, the multistep setup offers the possibility to vary the properties of the membranes by adjustment to the conditions of the protein solution. Diafiltration systems are also possible in this multistep setup by adding in between the filtration stages [36]. Despite the more complex setup with additional pumps, the SPTFF diafiltration provides many advantages like reduced buffer volume and less shear stress due to pumping of the target molecule [37]. Commercially available ultrafiltration modules were established recently [38] and still offer potential to be optimized. Vendor data provide strategies and experimental data for using their modules [39,40], but in order to create an optimal process, additional experiments are needed for the chosen system. These diagrams show the general 
behavior like in Figure 2a, where the flux is measured against the transmembrane pressure (TMP) or strategies for optimization depicted in Figure 2b.

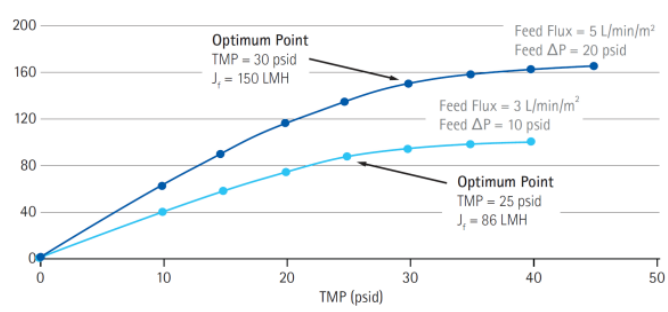

(a)
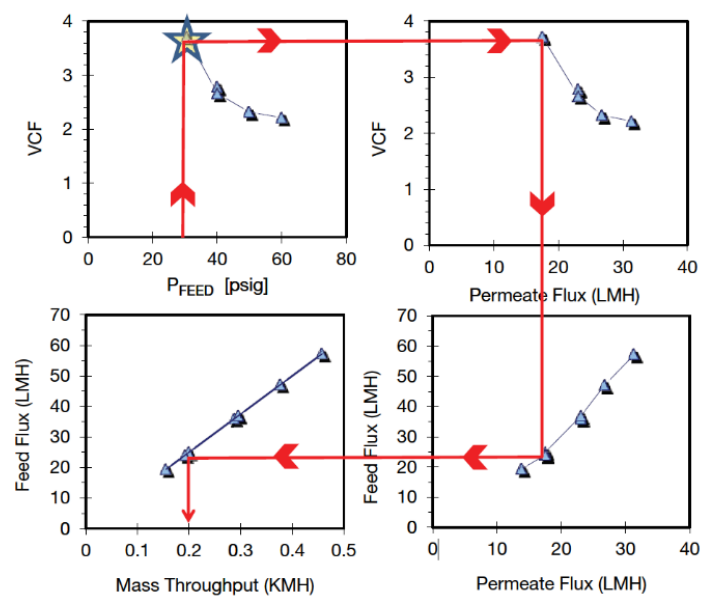

(b)

Figure 2. Commercial data: (a) determination of optimal process point reproduced with permission from Merck Millipore, 2012, (b) optimization strategy for SPTFF reproduced with permission from, Pall Corporation, 2014.

While the investigation of process parameters like feed pressure, retentate pressure and feed flow are mentioned in several studies [41-43] this work focusses on the modelling of SPTFF units in order to reduce experimental efforts significantly and to find a robust operation optimum under $\mathrm{QbD}$. This is performed based on experimental work, literature data, and design of commercially available modules. Developments of process variables like concentration, flux, or pressure, based on modelling are investigated and by using a model for process optimization, the experimental effort can be drastically reduced, which is especially relevant for multiparameter dependent unit operations. With a systematic approach, modelling can substitute experiments and accelerate the process design [29,44,45]. For this study an experimentally validated physico-chemical model [1] is enhanced and transferred. The model describes the mass transfer through the channel with a mass balance assuming loss in volume stream resulting in lower velocity of the retentate. Furthermore, mass transfer to the membrane is described by using the Stagnant Film Model (SFM) and through the membrane by the Osmotic Pressure Model (OPM) or Boundary Layer Model (BLM). This model-based approach provides the possibility to visualize critical process points for the ultrafiltration step. With this visualization a process design of ultrafiltration modules becomes more reasonable and in a subsequent step the SPTFF module can be designed a priori.

\section{Theory}

\subsection{Model Development}

The modelling approach presented is mainly based on previous validated models [2-4], especially [1].

\subsubsection{Concentration Polarization}

One of the main effects for tangential flow filtration is the concentration polarization, which leads to reduced permeate flux and low retentate concentrations. This effect is described by Michaels [46] with the SFM.

$$
\mathrm{J}_{\mathrm{V}}=\mathrm{k}_{\mathrm{f}} \cdot \ln \left(\frac{\mathrm{c}_{\mathrm{M}}}{\mathrm{c}_{\mathrm{B}}}\right)
$$


In this equation $\mathrm{J}_{\mathrm{v}}$ is the volumetric flux through the membrane, $\mathrm{k}_{\mathrm{f}}$ is the mass transfer coefficient describing the ratio of diffusion coefficient $\mathrm{D}$ and the boundary layer thickness $\delta, \mathrm{c}_{\mathrm{M}}$ represents the concentration of the target component at the membrane, and $\mathrm{c}_{\mathrm{B}}$ is the concentration in the bulk phase. The concentration polarization and therefore the flux through the membrane are affected by surrounding conditions changed due to the solution and the hydrodynamic influences. The concentration at the membrane should not reach the gel concentration. If the target molecule reaches this critical process point, a layer is formed resulting in a membrane layer on top of the membrane resulting in a minimized flux. The gel concentration of the protein is described in literature or must be determined experimentally.

\subsubsection{Osmotic Pressure Model}

To describe the mass transport through the membrane the OPM is chosen. Because of the significant influences of the surrounding buffer with the target molecule the osmotic pressure has to be considered $[1,5,11,46-48]$. The osmotic pressure difference between the solutions lowers the driving force affecting the mass transport through the membrane. The resulting flux is calculated by incorporating the osmotic pressure into Darcy's Law. With the additional assumption of $100 \%$ retention for the target molecule the flux is finally described by Equation (2) [1]:

$$
\mathrm{J}_{\mathrm{v}}=\frac{\mathrm{TMP}-\mathrm{P}_{\mathrm{Osm}}}{\eta_{\mathrm{P}} \cdot \mathrm{R}_{\mathrm{M}}}
$$

where TMP is the transmembrane pressure, $P_{\text {Osm }}$ represents the osmotic pressure, $\eta_{p}$ describes the dynamic viscosity of the permeate, and $\mathrm{R}_{\mathrm{M}}$ represents the membrane resistance. Exemplary correlations for osmotic pressure (Equations (3) and (4)) are based on experiments and have to be screened for several conditions like $\mathrm{pH}$, molarity of salt, and concentration of target protein [1,12,49].

$$
\begin{gathered}
\mathrm{P}_{\mathrm{Osm}, \mathrm{BSA}}=\left[\mathrm{A}_{1} \cdot \mathrm{c}+\mathrm{A}_{2} \cdot \mathrm{c}^{2}+\mathrm{A}_{3} \cdot \mathrm{c}^{3}\right] \\
\mathrm{P}_{\mathrm{Osm}, \mathrm{IgG}}=\mathrm{R} \cdot \mathrm{T} \cdot\left[\mathrm{A}_{1} \cdot \mathrm{c}+\mathrm{A}_{2} \cdot \mathrm{c}^{2}+\mathrm{A}_{3} \cdot \mathrm{c}^{3}\right]
\end{gathered}
$$

In these correlations c stands for the local concentration, $\mathrm{A}$ are prefactors, $\mathrm{R}$ is the gas constant and $\mathrm{T}$ the local temperature. Exemplary values for two different target molecules are presented in (Table 1).

Table 1. Exemplary virial coefficients for the Osmotic pressure of bovine serum albumin (BSA) and immunoglobulin G (IgG).

\begin{tabular}{ccccc}
\hline Protein & A1 & A2 & A3 & Source \\
\hline BSA & $3.7 \times 10^{-1}$ & $-2.98 \times 10^{-3}$ & $1 \times 10^{-5}$ & {$[1]$} \\
IgG & $7 \times 10^{-3}$ & $2.6 \times 10^{-4}$ & $-4 \times 10^{-7}$ & {$[49]$} \\
\hline
\end{tabular}

The different osmotic pressure curves are shown in Figure 3.

\subsubsection{Boundary Layer Model}

As described in literature, concentration polarization is strongly influenced by pressure and flux. Both process parameters increase the concentration polarization effect [11]. Furthermore, high viscosities lower the diffusion coefficient which also leads to an increased concentration polarization effect [11]. The resistance of the boundary layer can have a significant influence on the filtration process for high pressure and high viscosities and must be considered in this case. A way to describe this effect is the Boundary Layer Resistance model (BLM) [47].

$$
\mathrm{J}_{\mathrm{v}}=\frac{\mathrm{TMP}-\mathrm{P}_{\mathrm{Osm}}}{\eta_{\mathrm{p}} \cdot\left(\mathrm{R}_{\mathrm{M}}+\mathrm{R}_{\mathrm{BL}}\right)}
$$


For this, another resistance term is added to the equation which lowers the mass transport through the membrane.

\subsubsection{Mass Transfer Coefficient}

In order to calculate the mass transfer coefficient for Equation (1) the Sherwood correlation is used. This is needed because the conditions for the different cassettes strongly differ from each other in many variants like velocity or pressure. This forbids the assumption that the mass transfer coefficient stays nearly constant for each position point in the module. For these dependencies the well-established Sherwood correlation gives the opportunity to calculate a dynamic $\mathrm{k}_{\mathrm{f}}$.

$$
\mathrm{Sh}=\frac{\mathrm{k}_{\mathrm{f}} \cdot \mathrm{l}_{\mathrm{ch}}}{\mathrm{D}_{\mathrm{p}}}
$$

The Sherwood number Sh is also derived from the following calculation, consisting of the Schmidt number Equation (6) and the Reynolds number.

$$
\begin{gathered}
S h=s_{1}+s_{2} \cdot S_{c}^{s_{3}} \cdot \operatorname{Re}^{s_{4}} \\
S c=\frac{\eta_{\text {Sol }}}{\rho_{\text {Sol }} \cdot D_{P}} \\
\operatorname{Re}=\frac{u_{\text {eff }} \cdot 1_{\mathrm{ch}} \cdot \rho_{\mathrm{Sol}}}{\eta_{\mathrm{Sol}}}
\end{gathered}
$$

The necessary correlation coefficients for Equation (7) are summarized in Table 2.

Table 2. Sherwood correlations for different Reynolds numbers.

\begin{tabular}{ccccc}
\hline $\mathbf{s}_{\mathbf{1}}$ & $\mathbf{s}_{\mathbf{2}}$ & $\mathbf{s}_{\mathbf{3}}$ & $\mathbf{s}_{\mathbf{4}}$ & Source \\
\hline 1.664 & 0.33 & 0.33 & 0.33 & {$[1]$} \\
\hline
\end{tabular}

The dynamic viscosity of the solution changes during the filtration slightly with temperature and more so with the increase of the target protein concentration. For this dependency on concentration, different correlations are mentioned in literature. For bovine serum albumin (BSA) an empirical equation is applicable [1].

$$
\eta_{\text {Sol }}=1 \cdot 10^{-6} \cdot c^{3}-3 \cdot 10^{-4} \cdot c^{2}+4.11 \cdot 10^{-2} \cdot c
$$

In contradiction to the BSA correlation, for immunoglobulin G (IgG) the Mooney equation variations are used [12].

$$
\frac{\eta_{\text {Sol }}}{\eta_{p}}=\exp \left(\frac{b \cdot c}{1-\left(\frac{c}{c_{\text {Max }}}\right)}\right)
$$

For $\mathrm{b}$, the value 1.19 is chosen and for the maximal concentration, $800 \mathrm{~g} / \mathrm{L}$ is used based on [13]. The resulting graphs are visualized in Figure $3 \mathrm{~b}$.

The molar diffusion coefficient depends on the molecular weight of the protein and is calculated with Equation (12) [48]:

$$
\mathrm{D}_{\mathrm{P}}=8.314 \cdot 10^{-8}\left[\frac{\mathrm{cm} \cdot \mathrm{g}^{\frac{4}{3}}}{\mathrm{~K} \cdot \mathrm{s}^{2} \cdot \mathrm{mol}^{\frac{1}{3}}}\right] \cdot \frac{\mathrm{T}}{\eta \cdot \mathrm{M}^{\frac{1}{3}}}
$$

The effective velocity is derived from Equation (13):

$$
\mathrm{u}_{\mathrm{eff}}=\frac{\dot{\mathrm{V}}}{\mathrm{A}}=\frac{\dot{\mathrm{V}}}{\mathrm{d}_{\mathrm{h}} \cdot \mathrm{w}_{\mathrm{ch}}}
$$


with $\mathrm{V}$ as the volume flow and $\mathrm{A}$ as the cross-sectional area. The cross-sectional area is the product of the hydraulic diameter and the width of the membrane channel. In case of an ultrafiltration cassette this cross-sectional area is described by the hydraulic diameter and the width of the screen $[50,51]$. In this work it is assumed that the mass transport through the membrane leads to a reduced effective velocity while the volume of the membrane channel stays constant.

$$
\mathrm{u}_{\text {eff }}=\frac{\dot{\mathrm{V}}_{\mathrm{F}}}{\mathrm{A}}-\mathrm{J}_{\mathrm{v}}
$$

\subsubsection{Pressure Drop}

The transmembrane pressure for each location in the membrane channel is strongly depending on the pressure drop. The pressure loss is defined as the difference between incoming and outgoing pressure for the considered section.

$$
\Delta \mathrm{p}=\mathrm{p}_{\text {in }}-\mathrm{p}_{\text {out }}
$$

This pressure loss is influenced by the geometry of the membrane. In this work the dependency on geometry is described by using the dimensionless drag coefficient $c_{d}$ membrane [46-48,50,51], with $d_{h}$ being the hydraulic diameter of the membrane.

$$
\Delta \mathrm{p}=\frac{\mathrm{c}_{\mathrm{d}} \cdot \rho_{\text {Solution }} \cdot \mathrm{u}_{\mathrm{eff}}{ }^{2} \cdot 1_{\mathrm{ch}}}{2 \cdot \mathrm{d}_{\mathrm{h}}}
$$

The drag coefficient $c_{d}$ is calculated from the plot over the Reynolds number Equation (17).

$$
c_{d}=X_{c} \cdot \operatorname{Re}^{Y_{c}}
$$

with $X_{c}$ and $Y_{c}$ as experimental parameters, which must be determined for each geometry [50].

\subsection{Transferarbility of Molecules}

Comparing different target components, a general transferability between systems is desired. While the membrane geometries and setup are independent from protein solutions, properties of viscosity and concentration are depicted for two target molecules in Figure 3.

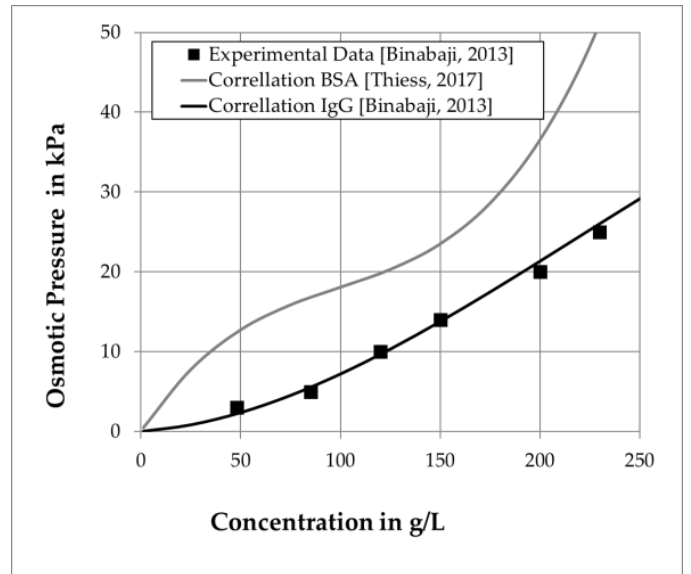

(a)

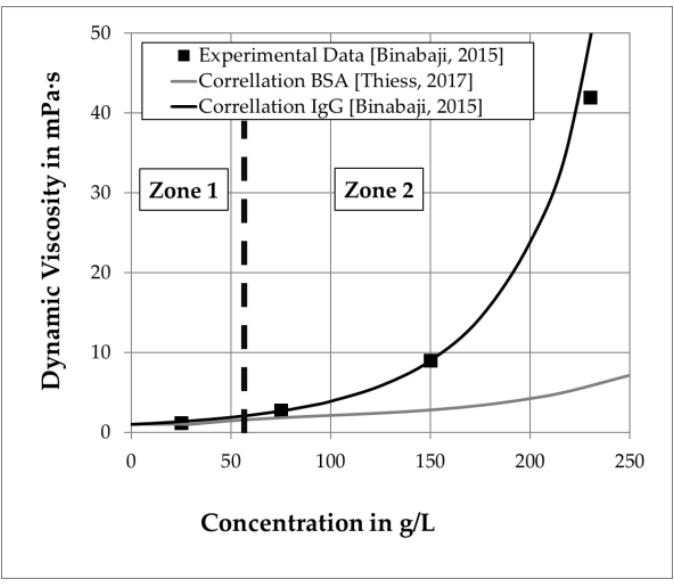

(b)

Figure 3. Dependency of process variables on protein concentration (a) osmotic pressure [1,49] and (b) dynamic viscosity $[1,12]$.

It is obvious that the effects, based on these correlations [1,12,49] for BSA and IgG, have negligible impact in smaller concentration regions. For this, Figure $3 \mathrm{~b}$ is divided into two zones. If a filtration 
experiment is executed in zone one, where the concentration does not exceed around $50 \mathrm{~g} / \mathrm{L}$, the filtration behavior is nearly the same, under the assumption that both molecules are completely retained.

\subsection{Membrane Modules}

In this study, SPTFF modules based on plate-and-frame ultrafiltration cassettes are investigated. The channels consist of frames in the beginning and in the end of the membranes. In addition, screens are inserted in between the membrane layers acting as spacers and increase mixing of the flow. These screens are either directly connected to the membrane or are suspended to achieve an enhanced channel height. While frames of the channel only vary in their height, screens may vary in thread diameter (warp and weft), thread distance, flow attack angle, mesh angle [50,52]. In addition, the screens could be used in permeate channels likewise to the feed channel. The distance between the membranes is described by the free channel height. In case of suspended screens, this channel height is increased by additional frame heights due to the TMP [1].

\subsection{Transfer of Modelling Approach to SPTFF}

For this study the validated Tangential Flow Filtration (TFF) model based on previous work of $[3,4]$ and [1] is transferred and enhanced. Because of the change of concentration factor dependency from time of processing to length of the filtration path, the model has to comprise several sub-models for tanks (feed, permeate, retentate), membranes and junctions (see Figure 4). The membrane model includes a mass balance for the transport through the channel, the Stagnant Film Model, the Osmotic Pressure Model or Boundary Layer Model. Additionally, equations for the pressure drop and the effect of the channel- and spacer-geometries are implemented. The tank model includes a mass balance, while the junctions model contains distribution equations to split and unite the parallel streams in between stages. Parallel membranes for each stage are calculated equally. For this study it is assumed that the feed flow is divided into equal parts. The used SPTFF concept is based on the commercial four-in-series design of Pall Cadence ${ }^{\mathrm{TM}}$ modules [39], which is shown in Figure 4.

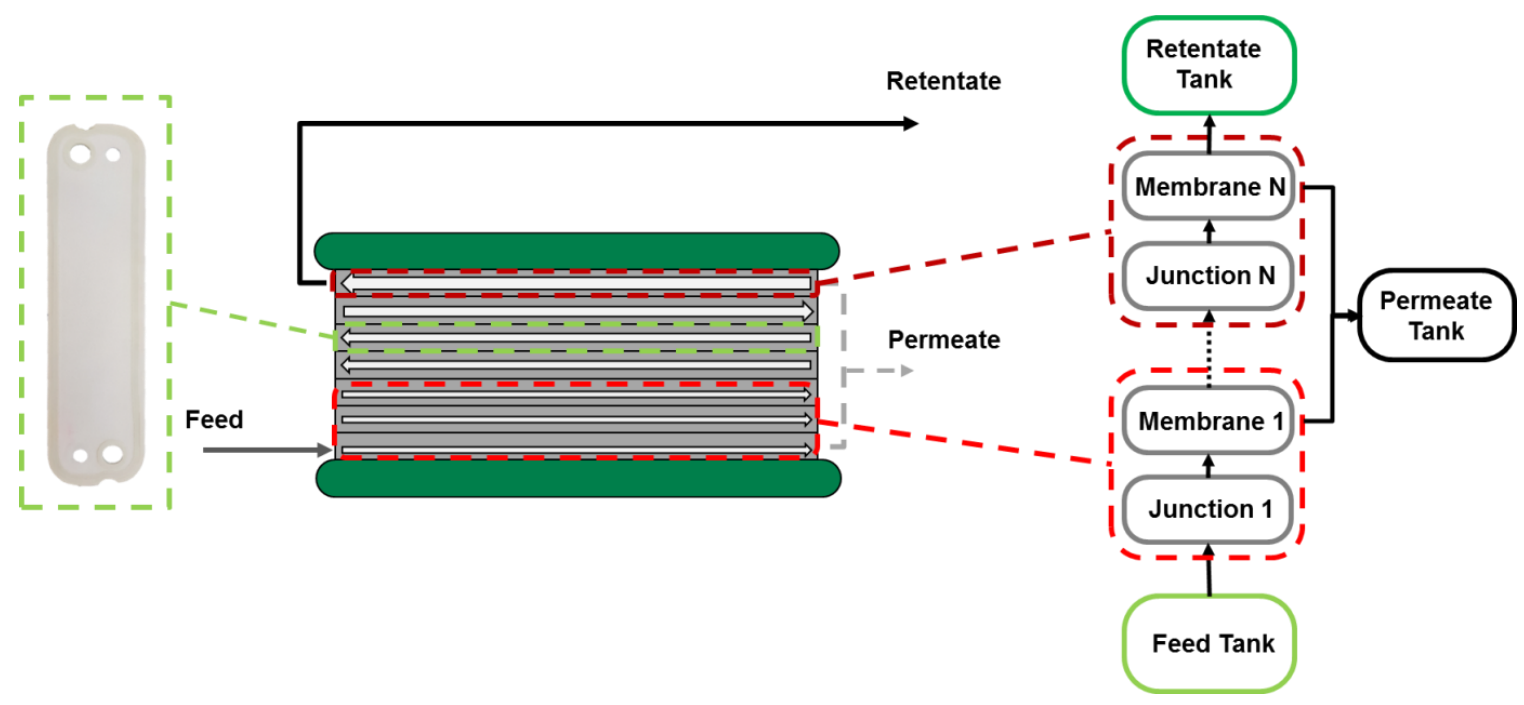

Figure 4. SPTFF module modelling approach.

The SPTFF module consists of several filtration stages. Each stage may vary in the number of parallel membrane cassettes and gives the possibility to vary internal geometries of the used cassettes in each stage as well. In this first approach the geometries are kept equal for each stage, but it offers the possibility to vary the setup to increase productivity. The selected setup uses three membranes in stage one, two membranes in stage two, and one membrane each in stages three and four. 


\subsection{Experimental Setup}

The validation examined by a setup compromising all relevant data for the axial development after each stage of the membrane. By splitting a complete four-in-series module into four single stages, the axial development of several process variables can be visualized and tracked. An exemplary setup for model validation, based on a four-in-series setup, is shown in Figure 5.

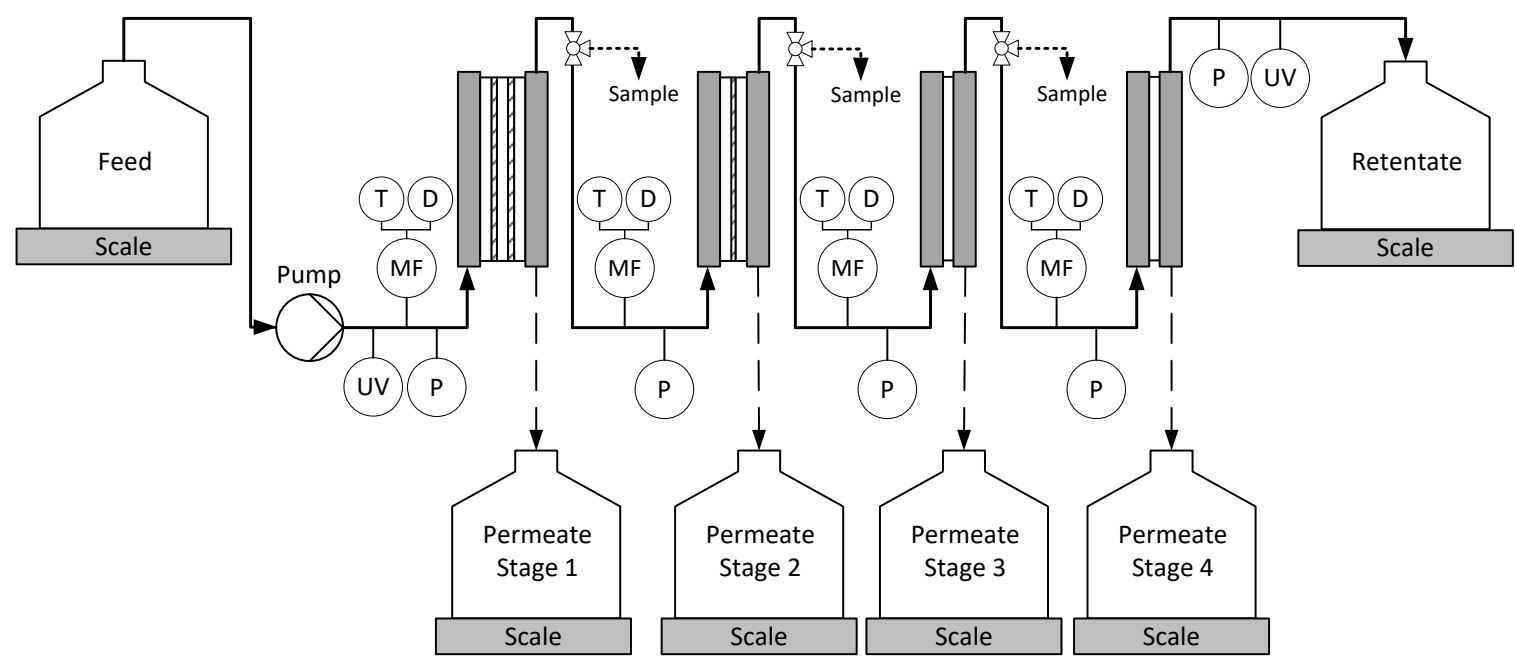

Figure 5. Experimental setup for model validation of four-in-series.

To achieve necessary information on the process, the measurements of pressure $(\mathrm{P})$ and mass flow (MF) are relevant after each SPTFF-stage. The measurement of the mass flows is possible by monitoring the weight development of the different streams (feed, retentate, permeate) and additionally with inline mass flow controllers in between the different filtration stages, which also measure temperature (T) and density (D). Temperature and density are only relevant for the system if they have a dramatic change during the experiment and therefore have influences on the viscosity, but in case of this study they are not essential for the used models to describe mass transport and pressure drop.

For validation of the model the smallest commercial membrane cassettes, with the minimal number of parallel channels in each cassette are used. This reduces possible influences due to internal parallel structures of multilayer cassettes. Furthermore, the first approach should show correct calculation of pressure drop and mass transfer through membrane. Therefore, it is necessary to perform experiments at high viscosity to measure the development of the pressure drop, which increases with higher viscosity values. For this, the light phase of an Aqueous Two-Phase Extraction (ATPE) step is adequate. The ATPE is a continuous harvesting step in an alternative DSP for monoclonal antibodies $[53,54]$. The concentration of the target monoclonal is smaller than $5 \mathrm{~g} / \mathrm{L}$ and therefore solution properties like increasing viscosity and osmotic pressure have a minor impact.

\section{Material \& Methods}

\subsection{Filtration Setup}

For experimental work $30 \mathrm{kDa}$ TangenX ${ }^{\mathrm{TM}}$ Pro cassettes (Repligen, Waltham, MA, USA) with an area of $100 \mathrm{~cm}^{2}$ and L-Screen were used. Each single membrane and membrane stack were inserted into membrane holders, with an $1 / 8^{\prime \prime}$ in and outlets. For pumping a gear pump type MV-Z (Ismatec, Wertheim, Germany) was used with $1 / 8^{\prime \prime}$ tubing for the whole setup in between the filtration stages.

\subsection{Media}

As feed medium for the experiments a viscous cell free light phase, consisting of polyethylene (PEG) glycol 400 (Merck KGaA, Darmstadt, Germany), phosphate buffer and cell medium was used. 
For Clean Water Resistance Tests (CWRT), purified water was acquired with the Sartorius ${ }^{\circledR}$ arium ${ }^{\circledR}$ 157 pro (Sartorius ${ }^{\circledR}$, Göttingen, Germany).

\subsection{Analytics}

For inline measurements five pressure transmitters A08 (Sensor-Technik Wiedemann, Kaufbeuren, Germany) and four Mini Cori-Flow ${ }^{\mathrm{TM}}$ M14 (Bronkhorst High-Tech BV, Ruurlo, The Netherlands) massflow controllers were used. In addition, the weight development of feed, retentate and all permeate streams were measured with PCE-TB 6 scales (PCE Deutschland GmbH, Meschede, Germany). The concentration of the target protein was quantified by Protein A chromatography (PA ID Sensor Cartridge, Applied Biosystems, Bedford, MA, USA). For loading, Dulbecco's PBS buffer (Sigma-Aldrich, St. Louis, MO, USA) was used at pH 7.4 and at $\mathrm{pH} 2.6$ as an elution buffer. The absorbance was monitored at $280 \mathrm{~nm}$. The size exclusion chromatography was performed by using a Yarra ${ }^{\mathrm{TM}} 3 \mu \mathrm{m}$ SEC-3000 column (Phenomenex Ltd., Aschaffenburg, Germany) with $0.1 \mathrm{M} \mathrm{Na}_{2} \mathrm{SO}_{4}, 0.1 \mathrm{M} \mathrm{Na}_{2} \mathrm{HPO}_{4}$, and $0.1 \mathrm{M} \mathrm{NaH}_{2} \mathrm{PO}_{4}$ (Merck KGaA, Germany) as a buffer system.

\subsection{Clean Water Resistance Tests}

For measuring the intrinsic membrane resistance three different cassettes were measured and in addition parallel setups are investigated. This requires the measurement of transmembrane pressure versus flux of purified water for at least three different pressures. The different transmembrane pressures were reached by varying the motor speed of the pump. Furthermore, between each repetition of a validation experiment, additional CWRTs of the whole SPTFF setup were performed. This on the one hand allows validation of the model for water filtration and on the other hand shows fouling tendencies after cleaning.

\subsection{Validation Experiments}

For transfer and validation of the SPTFF filtration unit three experiments were performed under the same conditions. The feed flow was adjusted to $25 \mathrm{~g} / \mathrm{min}$, resulting in a feed pressure near $4 \mathrm{bar}$, which was the maximum pressure allowed, based on vendor data. Each experiment was performed for $60 \mathrm{~min}$ until the valid steady-state was achieved and during the experiments several samples were taken from the retentate. After each experiment the membranes were cleaned with $0.5 \mathrm{M} \mathrm{NaOH}$ and stored in $0.2 \mathrm{M} \mathrm{NaOH}$.

\subsection{Datasets for Modelling}

For model validation and model-based predictions different datasets were applied, as mentioned before in this manuscript. All module related parameters, like geometries, resistances and drag factors were measured experimentally. Solution properties of the light phase were on the one hand measured experimentally (density, viscosity) and on the other hand were based on the correlations from [12,49]. In case of the model-based calculations the solution properties were for a $20 \mathrm{mM}$ buffer at $\mathrm{pH} 7$ [12,49]. The workflow for generating the necessary data is presented in Figure 6. 


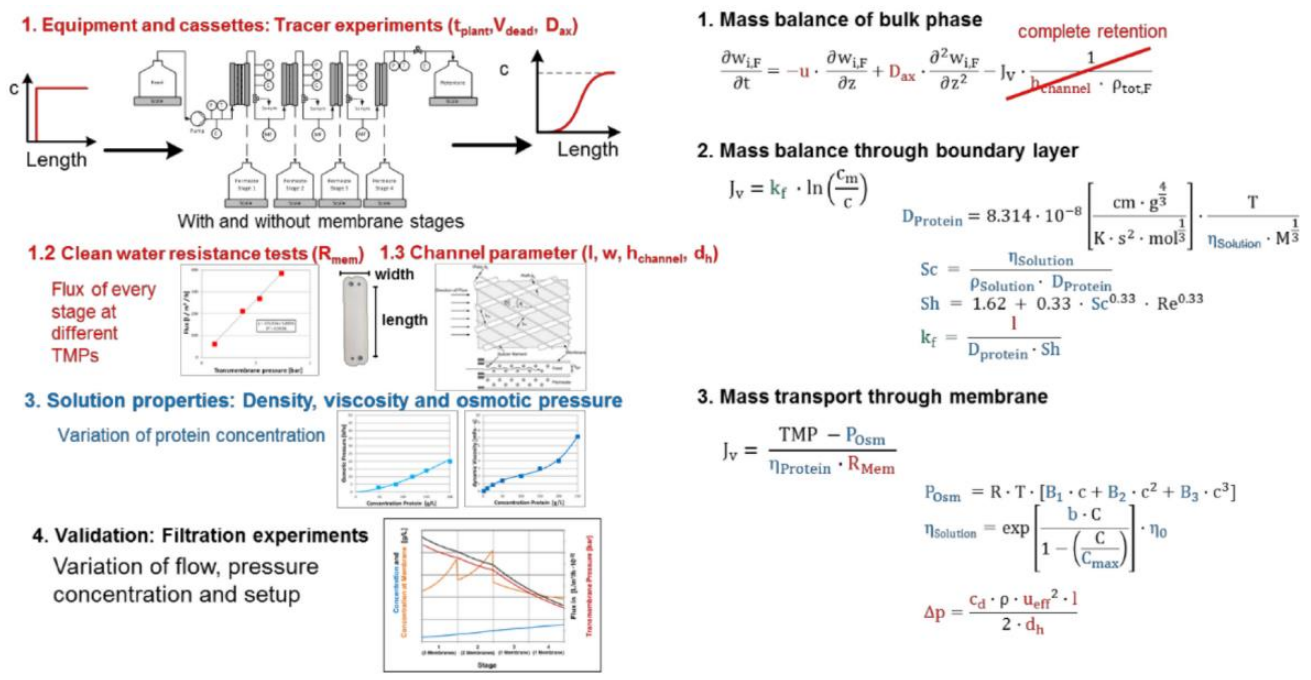

Figure 6. Workflow for process modelling of SPTFF [29].

Beginning with module related measurements, at first properties like dead volume, axial dispersion $\left(D_{a x}\right)$ and residence times had to be determined for the whole setup. In case of continuous perspective these parameters were only relevant in the starting period but are negligible in steady state. More of the aim was to predict a setup performance based on properties which could be determined from a single cassette. For this, a single cassette had to be measured regarding its geometrical data, because geometries of both spacer and channel lead to a hydraulic diameter $\left(\mathrm{d}_{\mathrm{h}}\right)$, the effective membrane area, and therefore effective velocity $\left(u\right.$ and $\left.u_{\text {eff }}\right)$. Furthermore, its effect on pressure drop $\left(c_{d}\right)$ and intrinsic membrane resistance $\left(R_{\text {Mem }}\right)$ must be determined via CWRTs. These module-based data are marked red in the figure above. The following step was the determination of solution properties (blue). This was started by the checking if full retention was reached for the given setup and therefore if the mass balance could be reduced. Then the concentration of the target molecule was variated in the given buffer system to gain information on density, viscosity and osmotic pressure development for this filtration step. Afterwards, the model was validated in a full setup in order to show that the simulation met the experimental data adequately. It is vital that no data was used from the validation experiments and everything was predicted from other experiments. By this systematic approach, a transferability of several membrane types on the one hand and protein systems on the other hand were given. For modeling and simulation Aspen Custom Modeler ${ }^{\mathrm{TM}}$ (Aspen Tech, Bedford, MA, USA) was used.

\section{Results and Discussion}

\subsection{Parameter Determination}

To determine the necessary parameter sets, membranes are characterized. This is achieved by measuring membrane area and geometry of spacers of the used modules. In addition, the membrane resistance is determined by performing CWRTs with three different single cassettes and parallel setups in a single stage. The results of the CWRTs in addition with the geometrical measurements lead to the drag factor coefficients. These parameters are displayed in Table 3 with data for viscosity and density of the solution. Table 4 shows the resulting membrane resistance values. 
Table 3. Module and Solution parameter.

\begin{tabular}{lcc}
\hline \multicolumn{1}{c}{ Parameter } & Unit & Value \\
\hline Membrane area per cassette & $\left(\mathrm{m}^{2}\right)$ & 0.01 \\
Hydraulic diameter & $(\mathrm{m})$ & $1.24 \cdot 10^{-4}$ \\
Drag factor coefficients & & \\
$\quad \mathrm{X}_{\mathrm{c}}$ & $(-)$ & $32.21 \pm 2.6$ \\
$\mathrm{Y}_{\mathrm{c}}$ & $(-)$ & $-0.77 \pm 0.02$ \\
Dynamic viscosity of permeate & & \\
$\quad$ Water & $(\mathrm{mPa} \cdot \mathrm{s})$ & 1 \\
$\quad$ Light Phase & $(\mathrm{mPa} \cdot \mathrm{s})$ & $7.4 \pm 0.6$ \\
Density & $(\mathrm{kg} / \mathrm{L})$ & $1.0 \pm 0.01$ \\
$\quad$ Water & $(\mathrm{kg} / \mathrm{L})$ & $1.1 \pm 0.01$ \\
$\quad$ Light Phase & & \\
\hline
\end{tabular}

Table 4. Intrinsic membrane resistance $\left(\mathrm{R}_{\mathrm{M}}\right)$.

\begin{tabular}{|c|c|c|c|c|}
\hline & \multicolumn{2}{|c|}{1 Cassette } & 2 Cassettes & 3 Cassettes \\
\hline $\begin{array}{c}\mathrm{R}_{\mathrm{M}} \\
{[1 / \mathrm{m}]} \\
10^{12}\end{array}$ & 2.25 & \pm 0.4 & 2.38 & 2.28 \\
\hline
\end{tabular}

On the one hand it is shown that the intrinsic membrane resistance of parallel setups lays in between the variance of single cassettes and that the reproducibility is given for the experiments. For the model the assumption of an equally split feed stream is adequate, and the average membrane resistance of a single cassette is used.

As discussed before, it is vital to check if the OPM is useful to describe the filtration process. For this a filtration process of light phase is compared with water filtration for a single cassette. The resulting TMP-Flux diagram is shown in Figure 7a. With knowledge of the flux, Equation (5) is solved for $\mathrm{R}_{\mathrm{BL}}$ and the resulting values are displayed in Figure $7 \mathrm{~b}$.

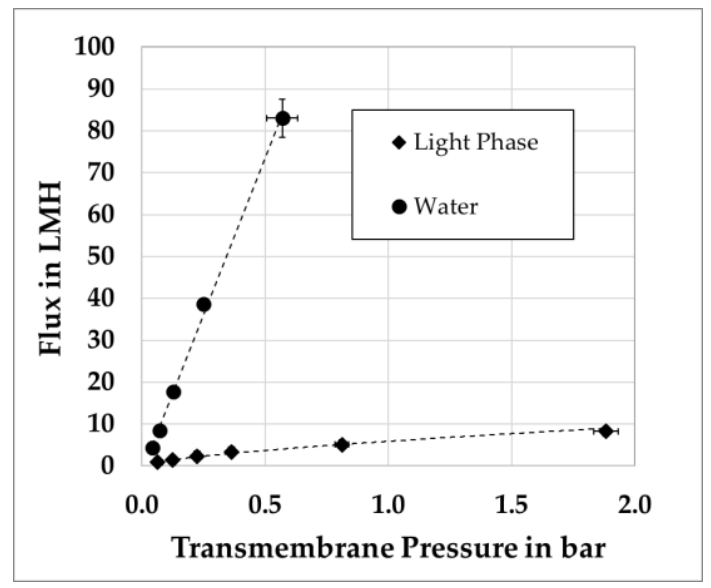

(a)

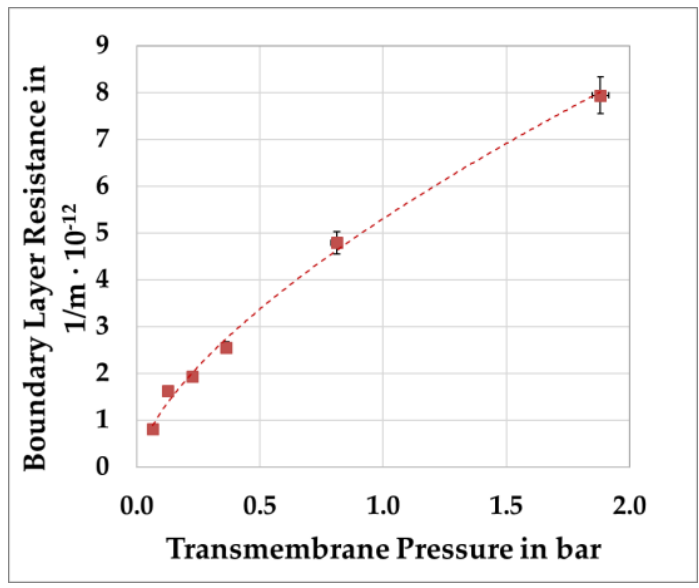

(b)

Figure 7. (a) Comparison flux vs. transmembrane pressure. (b) Development of boundary layer resistance.

Figure 7a illustrates clearly that even at low flow rates there is a significant deviation of around a factor of 10 in filtration performance between light phase and water. For this reason, the OPM is not applicable and an additional resistance is required, to describe the filtration of light phase. Figure $7 \mathrm{~b}$ shows that the resistance correlates with the TMP as main driving force of the system. For modelling the following equation is applied:

$$
\mathrm{R}_{\mathrm{Bl}}=\mathrm{X}_{\mathrm{R}} \cdot \mathrm{TMP}^{\mathrm{Y}_{\mathrm{R}}}
$$


with the values 5.31 for $X_{R}$ and 0.65 for $Y_{R}$ at an $R^{2}$ of 0.99 .

\subsection{Model Validation}

For model validation the determined parameters are initially used for pure water filtration. Figure 8 visualizes the development of flux (black) and transmembrane pressure (red) of the CWRTs for the SPTFF setup. The CWRT of the whole setup is performed three times like the validation experiments themselves. On the one hand the experimental data is shown as an average value of three repetitions, while on the other hand the simulated values are presented in lines. The horizontal axis represents the length of pathway from inlet to outlet. It is sectioned in stages, where each stage equals the length of one cassette. In case of the Tangen $\mathrm{X}^{\mathrm{TM}}$ a stage corresponds to $14.5 \mathrm{~cm}$. For this comparison the same operation parameters (feed flow: $144 ; 71 ; 13 \mathrm{~mL} / \mathrm{min}$, feed pressure: $1.25 ; 0.6$; 0.1 bar) are used.

The simulated values show great accordance with the experimental data, especially at lower flow rates. The steps of the simulated values in between the stages result from pressure drops due to inline mass flow controllers and additionally the change of numbers of membrane channels in each stage. In general, the experimental values of the first stage slightly exceeds the simulated values, while stages three and four show smaller values in comparison to the simulation. Nonetheless it is demonstrated that transmembrane pressure and filtration capabilities of water can be predicted by the model by knowing membrane properties and operation parameters.

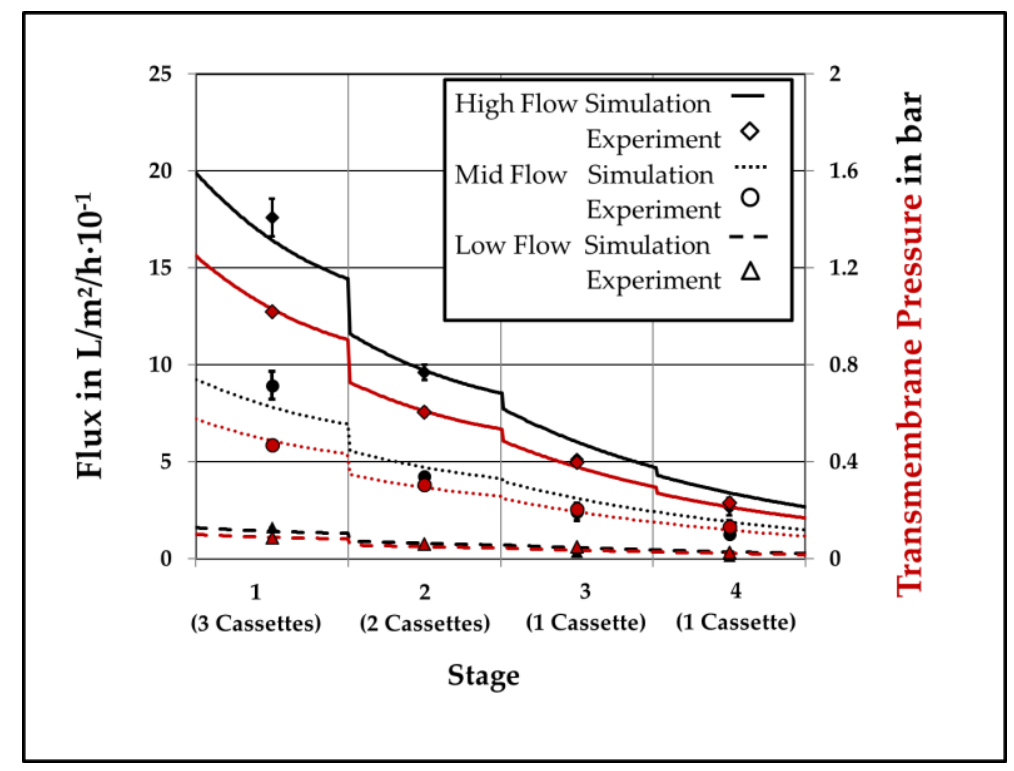

Figure 8. Comparison of flux and transmembrane pressure development of clean water resistance tests for experimental and simulated data.

For the filtration step of the light phase, it must be justified that the protein is kept in the retentate stream and does not pass the membrane. This is achieved by analyzing samples of feed, retentate permeate and an IgG standard with a size exclusion chromatography and the resulting chromatograms are visualized in Figure 9a. For comparison of volumetric concentration factors (VCF), the measured volume streams and protein A chromatography analysis results are compared and shown in Figure $9 \mathrm{~b}$. For the volume stream based VCF the feed flow is divided by the retentate flow and is measured inline, while the protein A chromatography results are measured offline. The development of the feed pressure during the experiments is also depicted in Figure $9 \mathrm{~b}$. 


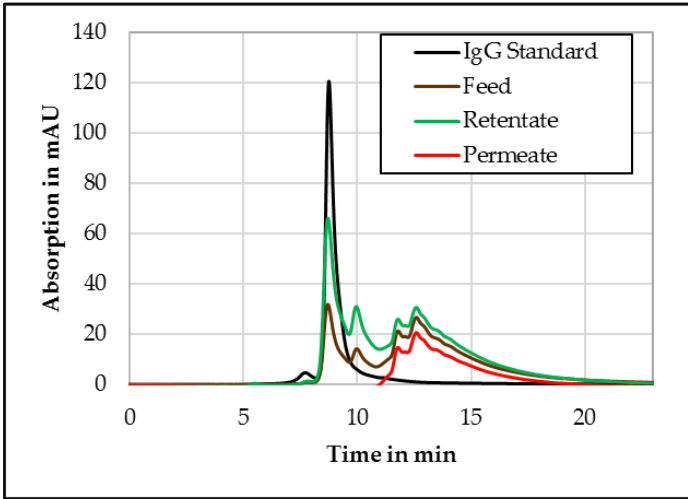

(a)

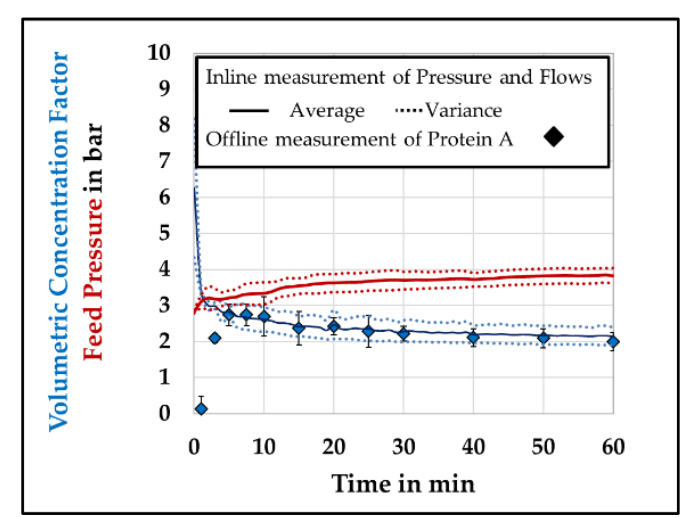

(b)

Figure 9. (a) Size exclusion chromatography analysis. (b) Development of volumetric concentration factor and feed pressure during experiments.

It is obvious that permeate only contains molecules which are significantly smaller than the target substance, which can be seen in Figure 9. The IgG is detected at around 9 min, and the signal of the permeate does not contain a peak in this time range, which proves full retention of the target molecule. For each experiment after 5 min the results from protein A chromatography overlap well with the volume flow-based values of ingoing and outgoing streams. Additionally, both graphs show that the SPTFF-system needs at least $10 \mathrm{~min}$ to create a nearly stationary process. Because the SPTFF should be continuous, the modelling approach focuses on the timeline after $10 \mathrm{~min}$, but a slight decrease in filtration performance with ongoing time is detectable. For model validation, the modelling is compared to the experiment. As operation parameter the average values after $10 \mathrm{~min}$ are chosen. The feed flow has a value of $23.8 \pm 0.9 \mathrm{~mL} / \mathrm{min}$ at a feed pressure of $3.70 \pm 0.23$ bar. As initial concentration $2.8 \pm 0.17 \mathrm{~g} / \mathrm{L}$ are found based on protein analysis for the three experimental repetitions. In Table 5 and Figure 10 the experimental values and the simulated ones are compared. In addition to Figure 8, Figure 10 contains the values for concentration (blue) of the target component. This change in concentration over length is calculated with the BLM. Furthermore, the concentration at the membrane (orange), which is not measurable and is calculated with the SFM. In contradiction to flux and transmembrane pressure, the experimental values for concentration are displayed at the beginning and in the end of each stage.

Table 5. Comparison of experimental and simulated process variables.

\begin{tabular}{ccc}
\hline & VCF & $\begin{array}{c}\text { Pressure Drop } \\
\text { [bar] }\end{array}$ \\
\hline Experiment & $2.31 \pm 0.12$ & $2.04 \pm 0.1$ \\
Model prediction & $2.10 \pm 0.11$ & $1.80 \pm 0.1$ \\
Difference & $9 \%$ & $11 \%$ \\
\hline
\end{tabular}




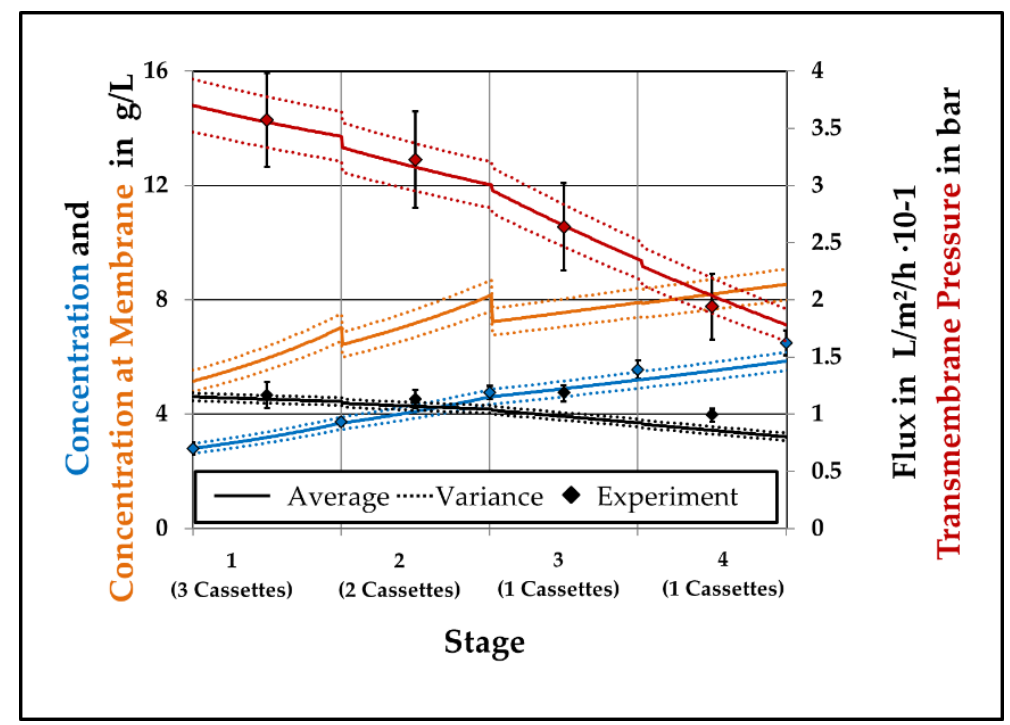

Figure 10. Profiles of concentration, flux and transmembrane pressure for modelled experiments of IgG in light phase.

The process variables of the simulation match the experimental data, especially in the first two stages containing the parallel membrane structures. In stage three and stage four the simulated flux is slightly lower compared to the experiments. This leads to a reduced concentration in the end of the filtration setup. In contradiction to Figure 9 the steps between the stages for flux and TMP are lower, due to minor change pressure drops resulting from inline MFCs. The concentration at the membrane wall is mainly affected by the flow regime and therefore the velocity of the solution. Because from stage one to two and stage two to three the streams are united, this leads to a different concentration. The development for stage three and four on the other hand has no step and displays a constant line, because no change of channel numbers takes place in between. The comparison of simulation and experiments shows that it is possible to calculate, predict and visualize the different process variables for the given SPTFF setup. Furthermore, transferring the batch model and therefore time dependent filtration to length depending filtration is performed and validated. Due to this, a model-based optimization of continuous filtration steps by knowing the relevant data of membrane geometries and solution properties is possible.

\subsection{Model Based Calculations}

\subsubsection{Transfer to Filtration of Low-Viscosity Solutions}

During the purification process of monoclonal antibodies, various ultrafiltration steps are possible. This leads to different process parameters for which the SPTFF modules have to be designed. These modules are affected, as shown in the previous section, by the starting concentration, solution properties, and the desired concentration for the next process step. One possibility is the increase of concentration after the perfusion step. For these calculations, solution properties of aqueous buffers from literature are used. Due to higher volume streams and lower viscosities, the boundary layer resistance is neglected for this study and the OPM is used in contradiction to the previous section. Furthermore, the several pressure drops based on inline analytics are not considered. The operation parameters for this study are a starting concentration of $1 \mathrm{~g} / \mathrm{L}$ and a feed pressure at resulting feed flow of $126.5 \mathrm{~mL} / \mathrm{min}$. The membrane resistance is taken from the experiments in Section 4.1 and has a value of $2.25 \cdot 10^{12} 1 / \mathrm{m}$. Figure 11 illustrates the axial profiles of concentration, flux and pressure. In addition to the standard membrane cassette setup, another "optimized" setup is compared. In this variation, another cassette is inserted in stage three in order to decrease the pressure drop, which can be seen in 
Figure 10. Due to this additional cassette the TMP should be maintained and the overall performance enhanced. Table 6 compares both variations based on their performance.

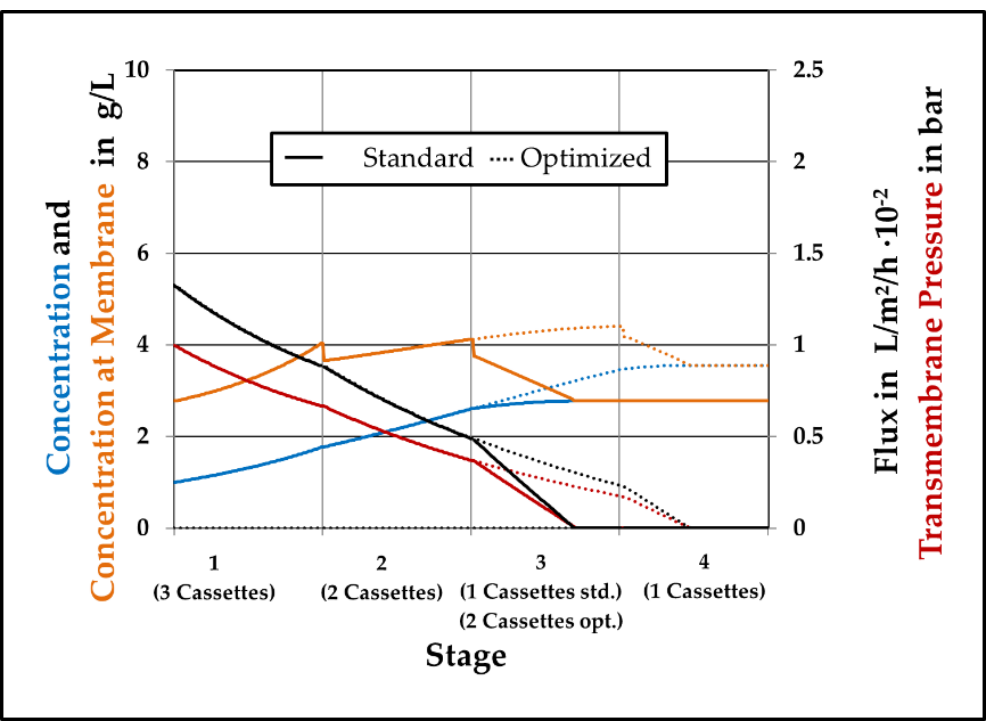

Figure 11. Calculation scenario: Comparison of standard (std.) and optimized (opt.) setup at 1 bar.

Table 6. Comparison of standard and optimized setup at 1 bar.

\begin{tabular}{lcccc}
\hline \multirow{2}{*}{ Parameter } & \multirow{2}{*}{ Unit } & \multicolumn{2}{c}{ Value } & \multirow{2}{*}{ Standard } \\
& & Optimized & Difference \\
\hline Membrane Area & $\left(\mathrm{m}^{2}\right)$ & 0.07 & 0.08 & $+14.2 \%$ \\
Final Concentration & $(\mathrm{g} / \mathrm{L})$ & 2.78 & 3.56 & $+28.1 \%$ \\
Retentate Flow & $(\mathrm{mL} / \mathrm{min})$ & 45.22 & 35.28 & $-21.9 \%$ \\
Permeate Flux & $\left(\mathrm{L} / \mathrm{m}^{2} / \mathrm{h}\right)$ & 67.84 & 66.71 & $-1.6 \%$ \\
\hline
\end{tabular}

We can see in Figure 11, that the system suffers a drastic pressure drop for both setups in this scenario. For the standard one it results in a static concentration in stage three, which makes the fourth stage irrelevant. With the insertion of an additional cassette in stage three the transmembrane pressure can be maintained and it results in a $28 \%$ higher concentration. In contradiction to increased concentration, the normalized flux shows a slight reduction, which is based on the increased area for the optimized setup. Focussing on final concentration as the target variable, the optimized setup enhances the filtration capability strongly by inserting another membrane cassette in stage three.

\subsubsection{Variation of Feed Pressure and Flow}

As a multi-parameter dependent process, the best parameter set for filtration has to be found. Since, an enhanced TMP leads to an increased flux, it is favorable to work at maximum feed pressure. By increasing the feed pressure, the feed flow rises as well. This again possibly results in a greater pressure drop. Therefore, a study of different feed pressures is necessary, in order to determine the optimal process point. For this work, the resulting feed flow, which depends on the feed pressure, is based on the values from the CWRTs and follows the development visualized in Figure 12a. The results of VCF, flux and pressure drop for both setups are depicted in Figure 12b. In addition, significant process points (A, B, C) are marked for further investigation. 


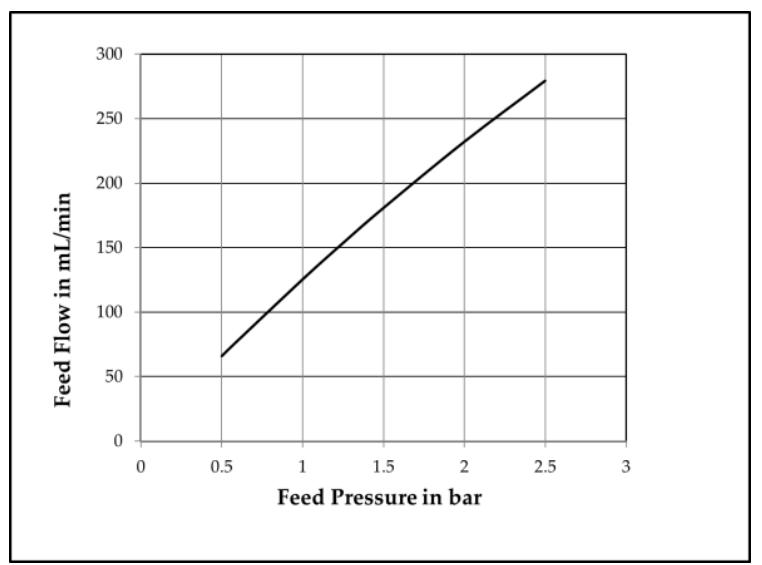

(a)

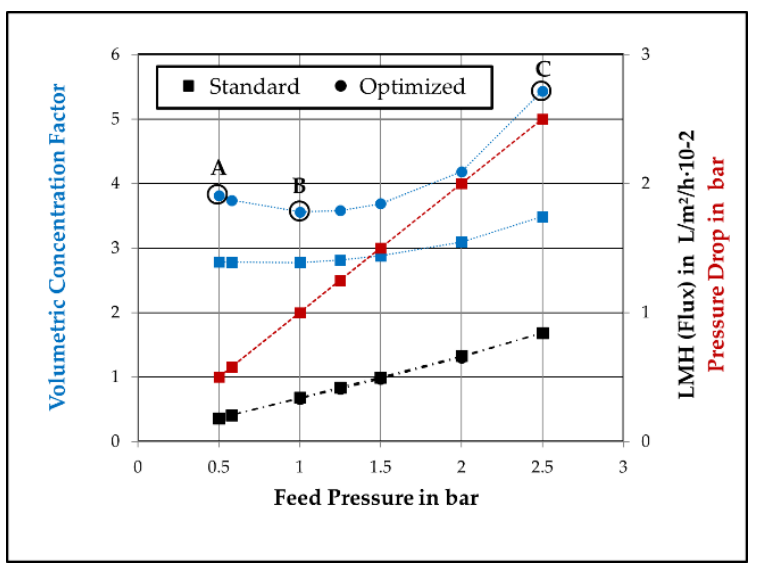

(b)

Figure 12. Calculation scenario: (a) Feed pressure vs. feed flow, (b) results based on pressure variation.

Figure $12 \mathrm{~b}$ displays the multi-parameter effects created by the increase of the inlet pressure. While the VCF rises with higher pressure, it is shown that there is a well performing operation parameter window with lower feed streams and pressures. Comparing it to the vendor data in Figure $2 b$, the increase of VCF with higher pressures does not meet the simulation and it is possible that the OPM is not applicable for high pressures and velocities, due to increased concentration polarization and additional resistances, which have to be considered. On the other hand, the increase of flux shows the same tendencies and the increased VCF at low pressures is shown.

For enhanced understanding of the axial profiles of the operation points A, B and C are illustrated in Figure 13. Mark A represents the operation point in the beginning, while operating at lowest feed flow. Mark B is the operation point with minimal VCF and mark C represents the operation point with greatest VCF working at highest feed pressure.

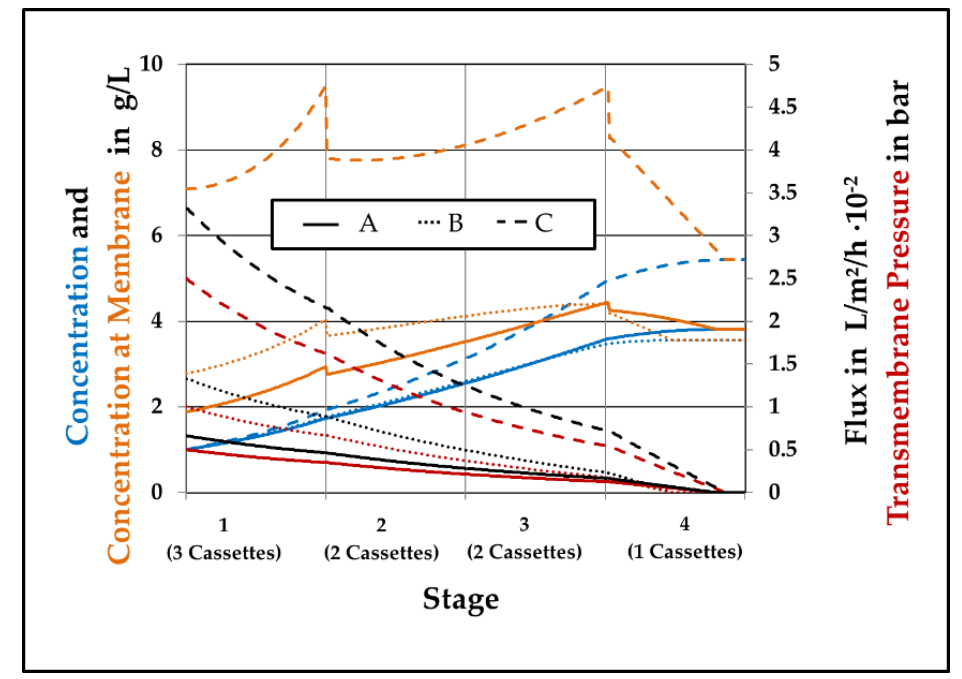

Figure 13. Calculation scenario: axial profiles of operation points A, B, C.

The axial profiles-in Figure 13-of operation point A and B show a minor decrease of the TMP and flux over the module. But in comparison to point A process point B shows a greater polarization effect, which probably leads to a reduced flux for the module. In contradiction to operation point $\mathrm{A}$ and $\mathrm{B}$, the TMP and flux profiles of operation point $\mathrm{C}$ contains a more drastic drop over the setup range. Moreover, its process parameters lead to an increased concentration at the membrane, also leading to additional possible resistances, which would lower the filtration capabilities with additional resistance. All scenarios show a complete loss of transmembrane pressure in the last stage. Under the 
given circumstances the filtration setup is not used efficiently. Based on the data it is also possible to reduce the setup by the last stage, because the change of concentration is negligible. By visualizing the axial profiles, an increase in understanding of these effects is achieved. Furthermore, interaction points for optimization get more transparent.

\subsubsection{Critical Process Variables}

An important factor in process design is the detection of critical process variables, which lead to fouling or other negative effects resulting in unused potential of the filtration module or unsatisfactory performance causing product quality losses in following steps. In case of SPTFF, a gel layer formation of the protein or reverse filtration resulting from high pressure drops are possible problems. In Figure 14 both cases are visualized based on simulation results for an increased starting concentration of $70 \mathrm{~g} / \mathrm{L}$ IgG.

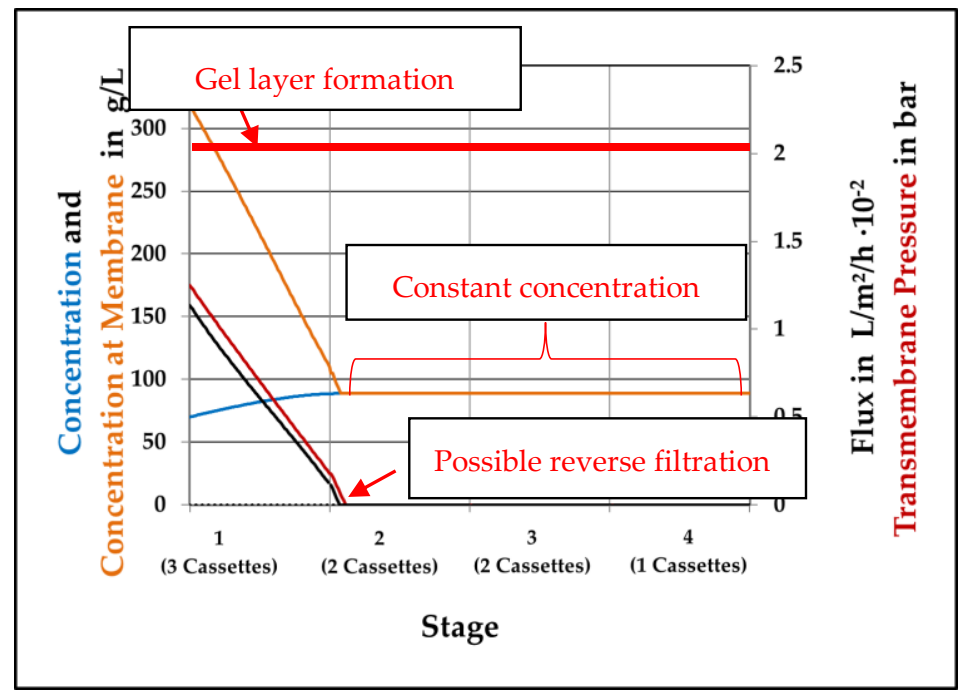

Figure 14. Critical process variables.

In stage one the concentration at the membrane exceeds the concentration of around $280 \mathrm{~g} / \mathrm{L}$. After this concentration a gel layer for IgG is formed, which is another resistance for the filtration and drastically reduce the concentrating performance. The other occurring problem is the strongly decreasing pressure ultimately leading to the negative TMP starting already in stage two. This would lead to a reverse filtration and therefore dilution of the product. In addition, the graph visualizes that the concentration is nearly constant after stage one.

With this model the gel layer and the reverse filtration are not calculated, but it is possible to detect and predict the problematic process points and developments in the SPTFF module. With this insight into a membrane unit, which is normally a black box, a better process comprehension is acquired leading to data driven decisions and $\mathrm{QbD}$. This gives the opportunity to use the potential of the module completely and create a control strategy based on model calculations.

\section{Conclusions}

In this study a versatile tool for continuous ultrafiltration process design and module optimization is developed. For this the filtration process is separated into membrane cassette depending variables (e.g., turbulence, intrinsic membrane resistance) and solution-based properties (e.g., viscosity, density, osmotic pressure). Even though both parameter sets are needed for the process variables like pressure drop and flux, they can be measured independently and are transferable. By feeding these parameter sets in the displayed model, the filtration performance can be predicted as shown in Section 4.1. This allows a model based integration and optimization as well as QbD. 
Furthermore, an exemplary model-based study is performed for a comparison of two different setups for filtration. It is shown how the membrane setup can be optimized for a better filtration step and on the processes are visualized and critical process conditions are presented. This calculation study again underlines the potential and usefulness of this model-based approach for the continuous SPTFF as multi-parameter optimization problem, but higher protein concentrations must be investigated. The rising effects of osmotic pressure and additional resistances due to, e.g., boundary layers, strongly influence the filtration results, but for this highly viscous protein solution at low concentration the transferability of batch membrane setups is proven, and the model is validated by the experiments sufficiently. The pressure drop can be calculated from the geometrical data, which makes the main driving force predictable. With this model it is also possible to perform setup variations (stage numbers, parallel membranes) and investigate influences of spacer or membrane geometries on the filtration process.

By knowing the properties of the membrane modules and solution properties, an ultrafiltration step can be designed a priori and integrated in any process sequence with less experimental effort, resulting in an accelerated process design with vastly reduced experiments and increased process understanding.

Author Contributions: M.J.H. performed the experiments, developed the model, did the simulations as well as wrote this paper. J.S. is responsible for conception and supervision.

Funding: The authors want to thank the Bundesministerium für Wirtschaft und Energie (BMWi), especially Dr. M. Gahr (Projektträger FZ Jülich), for funding this scientific work (Reference number: 03ET1365A).

Acknowledgments: We gratefully acknowledge the support of the ITVP lab-team especially Frank Steinhäuser and Volker Strohmeyer for their effort and support. In addition, we want to thank Holger Thiess for fruitful discussions.

Conflicts of Interest: The authors declare no conflict of interest.

\section{Symbols and Abbreviations}

A Factor for osmotic Pressure

c Concentration in the liquid phase, $\mathrm{g} / \mathrm{L}$

$\mathrm{c}_{\mathrm{M}} \quad$ Concentration at membrane, $\mathrm{g} / \mathrm{L}$

$\mathrm{C}_{\mathrm{B}} \quad$ Concentration in bulk phase, $\mathrm{g} / \mathrm{L}$

$\mathrm{d}_{\mathrm{h}} \quad$ Hydraulic diameter, $\mathrm{m}$

$\mathrm{D}_{\mathrm{p}} \quad$ Molecular diffusion coefficient, $\mathrm{m}^{2} / \mathrm{s}$

$\mathrm{J}_{\mathrm{v}} \quad$ Volumetric flux, $\mathrm{L} / \mathrm{m}^{2} / \mathrm{h}$

$\mathrm{k}_{\mathrm{f}} \quad$ Mass transfer coefficient, $\mathrm{m} / \mathrm{s}$

$\mathrm{L}_{\mathrm{ch}} \quad$ Length of channel, $\mathrm{m}$

$\mathrm{p}$ Pressure, bar

POsM Osmotic pressure, bar

$\mathrm{R}_{\mathrm{M}} \quad$ Resistance of Membrane, $1 / \mathrm{m}$

$\mathrm{R}_{\mathrm{BL}} \quad$ Resistance of Boundary layer, $1 / \mathrm{m}$

Sc Sherwood number, -

T Temperature, ${ }^{\circ} \mathrm{C}$

TMP Transmembrane pressure, bar

$\mathrm{u}_{\text {eff }} \quad$ Effective velocity, $\mathrm{m} / \mathrm{s}$

$\mathrm{V} \quad$ Volume, $\mathrm{dm}^{3} \mathrm{w}_{\mathrm{ch}}$, Width of channel, $\mathrm{m}$

$X_{C} \quad$ Factor for drag coefficient, -

$\mathrm{X}_{\mathrm{R}} \quad$ Factor for boundary layer resistance, $\mathrm{m} / \mathrm{bar}$

$Y_{C} \quad$ Exponent for drag coefficient, -

$Y_{R} \quad$ Exponent for boundary layer resistance, -

$\rho_{\text {Sol }} \quad$ density of solution, $g / L$

$\eta_{\text {Sol }}$ dynamic viscosity of solution, $\mathrm{g} / \mathrm{m} / \mathrm{s}$

$\eta_{\mathrm{p}} \quad$ dynamic viscosity of permeate, $\mathrm{g} / \mathrm{m} / \mathrm{s}$ 


\section{References}

1. Thiess, H.; Leuthold, M.; Grummert, U.; Strube, J. Module design for ultrafiltration in biotechnology: Hydraulic analysis and statistical modeling. J. Membr. Sci. 2017, 540, 440-453. [CrossRef]

2. Fröhlich, H.; Villian, L.; Melzner, D.; Strube, J. Membrane Technology in Bioprocess Science. Chem. Ing. Technol. 2012, 297. [CrossRef]

3. Grote, F.; Fröhlich, H.; Strube, J. Integration of Ultrafiltration Unit Operations in Biotechnology Process Design. Chem. Eng. Technol. 2011, 34, 673-687. [CrossRef]

4. Grote, F.; Fröhlich, H.; Strube, J. Integration of Reverse-Osmosis Unit Operations in Biotechnology Process Design. Chem. Eng. Technol. 2012, 35, 191-197. [CrossRef]

5. Charcosset, C. Membrane Processes in Biotechnology and Pharmaceutics; Elsevier: Oxford, UK, 2012; ISBN 978-0-444-56334-7.

6. Melin, T.; Rautenbach, R. Membranverfahren. Grundlagen der Modul-und Anlagenauslegung; Springer: Berlin, Germany; New York, NY, USA, 2007; ISBN 3540000712.

7. Teske, C.A.; Lebreton, B.; van Reis, R. Inline ultrafiltration. Biotechnol. Prog. 2010. [CrossRef] [PubMed]

8. Reis, R.; Zydney, A. Bioprocess membrane technology. J. Membr. Sci. 2007, 297, 16-50. [CrossRef]

9. Zobel, S.; Helling, C.; Strube, J. Adsorptionsprozesse in der biopharmazeutischen Industrie: Vergleich zwischen Chromatographie und Membranadsorbern. Chem. Ing. Technol. 2013, 85, 1370. [CrossRef]

10. Schwellenbach, J.; Zobel, S.; Taft, F.; Villain, L.; Strube, J. Purification of Monoclonal Antibodies Using a Fiber Based Cation-Exchange Stationary Phase: Parameter Determination and Modeling. Bioengineering 2016, 3, 24. [CrossRef]

11. Baker, R.W. Membrane Technology and Applications, 3rd ed.; Wiley: Chichester, UK, 2012; ISBN 978-0-470-74372-0.

12. Binabaji, E.; Ma, J.; Zydney, A.L. Intermolecular Interactions and the Viscosity of Highly Concentrated Monoclonal Antibody Solutions. Pharm. Res. 2015, 32, 3102-3109. [CrossRef]

13. Binabaji, E.; Ma, J.; Rao, S.; Zydney, A.L. Ultrafiltration of highly concentrated antibody solutions: Experiments and modeling for the effects of module and buffer conditions. Biotechnol. Prog. 2016, 32, 692-701. [CrossRef]

14. Lutz, H.; Arias, J.; Zou, Y. High concentration biotherapeutic formulation and ultrafiltration: Part 1 pressure limits. Biotechnol. Prog. 2017, 33, 113-124. [CrossRef] [PubMed]

15. Scopes, R.K. Protein Purification. Principles and Practice, 3rd ed.; Springer: Berlin/Heidelberg, Germany, 1994; ISBN 0-387-94072-3.

16. Roque, A.C.A.; Lowe, C.R.; Taipa, M.A. Antibodies and genetically engineered related molecules: Production and purification. Biotechnol. Prog. 2004, 20, 639-654. [CrossRef] [PubMed]

17. Sommerfeld, S.; Strube, J. Challenges in biotechnology production-Generic processes and process optimization for monoclonal antibodies. Chem. Eng. Process. Process Intensif. 2005, 44, 1123-1137. [CrossRef]

18. Warikoo, V.; Godawat, R.; Brower, K.; Jain, S.; Cummings, D.; Simons, E.; Johnson, T.; Walther, J.; Yu, M.; Wright, B.; et al. Integrated continuous production of recombinant therapeutic proteins. Biotechnol. Bioeng. 2012, 109, 3018-3029. [CrossRef] [PubMed]

19. Konstantinov, K. Continous bioprocessing: An interview with Konstantin Konstantinov from Genzyme. Interviewed by Prof. Alois Jungbauer and Dr. Judy Peng. Biotechnol. J. 2011, 6, 1431-1433. [CrossRef] [PubMed]

20. Konstantinov, K.B.; Cooney, C.L. White Paper on Continuous Bioprocessing May 20-21 2014 Continuous Manufacturing Symposium. J. Pharm. Sci. 2015, 104, 813-820. [CrossRef] [PubMed]

21. Subramanian, G. Continuous Biomanufacturing. Innovative Technologies and Methods; Wiley-VCH: Weinheim, Germany, 2018; ISBN 978-3-527-34063-7.

22. Zydney, A.L. Continuous downstream processing for high value biological products: A Review. Biotechnol. Bioeng. 2016, 113, 465-475. [CrossRef]

23. CDER. Guidance for Industry: PAT -A Framwork for Innovative Pharmaceutical Development; CDER-FDA: Silver Spring, MD, USA, 2004.

24. CDER; CBER; FDA; USDHHS. ICH, Guidance for Industry; Q9: Quality Risk Management; Center for Drug Evaluation and Research; Center for Biologics Evaluation and Research; Food and Drug Administration: Rockville, MD, USA, 2006. 
25. European Medicines Agency; Food and Drug Administration. EMA-FDA Pilot Program for Parallel Assessment of Quality by Design Applications; FDA: Silver Spring, MD, USA, 2011.

26. Lee, S.L. Regulatory Initiatives for Supporting Innovation in Pharmaceutical Manufacturing; Presented ad PDA Manufactruing Science Workshop; Washington, DC, USA, 2015.

27. Woodcock, J. Modernizing pharmaceutical manufacturing-Continuous manufacturing as a key enabler. In Proceedings of the MIT-CMAC International Symposium on Continuous Manufacturing of Pharmaceuticals, Cambridge, MA, USA, 20 May 2014.

28. Strube, J.; Ditz, R.; Kornecki, M.; Huter, M.; Schmidt, A.; Thiess, H.; Zobel-Roos, S. Process intensification in biologics manufacturing. Chem. Eng. Process. Process Intensif. 2018, 133, 278-293. [CrossRef]

29. Zobel-Roos, S.; Schmidt, A.; Mestmäcker, F.; Mouellef, M.; Huter, M.; Uhlenbrock, L.; Kornecki, M.; Lohmann, L.; Ditz, R.; Strube, J. Accelerating Biologics Manufacturing by Modeling or: Is Approval under the QbD and PAT Approaches Demanded by Authorities Acceptable Without a Digital-Twin? Processes 2019, 7, 94. [CrossRef]

30. Zobel, S.; Helling, C.; Ditz, R.; Strube, J. Design and Operation of Continuous Countercurrent Chromatography in Biotechnological Production. Ind. Eng. Chem. Res. 2014, 53, 9169-9185. [CrossRef]

31. Schmidt, A.; Strube, J. Process Development and Scale-up of Aqueous Two-Phase Extraction as Clarification and Capture Step in the Manufacturing of Biologics. Chem. Eng. Technol. 2018, 90, 1229-1230. [CrossRef]

32. Eggersgluess, J.K.; Richter, M.; Dieterle, M.; Strube, J. Multi-Stage Aqueous Two-Phase Extraction for the Purification of Monoclonal Antibodies. Chem. Eng. Technol. 2014, 37, 675-682. [CrossRef]

33. Jungbauer, A. Continuous downstream processing of biopharmaceuticals. Trends Biotechnol. 2013, 31, 479-492. [CrossRef]

34. Cheryan, M. Ultrafiltration and Microfiltration Handbook; Technomic Pub. Co.: Lancaster, PA, USA, 1998; ISBN 1566765986.

35. Dizon-Maspat, J.; Bourret, J.; D’Agostini, A.; Li, F. Single pass tangential flow filtration to debottleneck downstream processing for therapeutic antibody production. Biotechnol. Bioeng. 2012, 109, 962-970. [CrossRef] [PubMed]

36. Rucker-Pezzini, J.; Arnold, L.; Hill-Byrne, K.; Sharp, T.; Avazhanskiy, M.; Forespring, C. Single pass diafiltration integrated into a fully continuous mAb purification process. Biotechnol. Bioeng. 2018, 115, 1949-1957. [CrossRef]

37. Nambiar, A.M.K.; Li, Y.; Zydney, A.L. Countercurrent staged diafiltration for formulation of high value proteins. Biotechnol. Bioeng. 2018, 115, 139-144. [CrossRef]

38. Petrone, J. Advancing Continuous Concentration with Patented Cadence ${ }^{\mathrm{TM}}$ Single-Pass Tangential Flow Fitration; PALL: Nassau County, NY, USA, 2017.

39. Pall Life Sciences. Application Note-Volume Reduction and Process Optimization with Cadence ${ }^{\mathrm{TM}}$ Inline Concentrator; Pall Life Sciences: PALL: Nassau County, NY, USA, 2013.

40. EMD Millipore. Application Note-A Hands-On Guide to Ultrafiltration/Diafiltration Optimization Using Pellicon ${ }^{\circledR}$ Cassettes. Available online: http://www.merckmillipore.com/DE/de/ps-learning-centers/ ultrafiltration-learning-center/optimization-process-simulation/d_eb.qB.ZWQAAAFAUV8ENHoL,nav? Referrer (accessed on 20 August 2018).

41. Arunkumar, A.; Singh, N.; Peck, M.; Borys, M.C.; Li, Z.J. Investigation of single-pass tangential flow filtration (SPTFF) as an inline concentration step for cell culture harvest. J. Membr. Sci. 2017, 524, 20-32. [CrossRef]

42. Baek, Y.; Singh, N.; Arunkumar, A.; Borys, M.; Li, Z.J.; Zydney, A.L. Ultrafiltration behavior of monoclonal antibodies and Fc-fusion proteins: Effects of physical properties. Biotechnol. Bioeng. 2017, 114, 2057-2065. [CrossRef]

43. Sixt, M.; Strube, J. Systematic Design and Evaluation of an Extraction Process for Traditionally Used Herbal Medicine on the Example of Hawthorn (Crataegus monogyna JACQ.). Processes 2018, 6, 73. [CrossRef]

44. Sixt, M.; Strube, J. Systematic and Model-Assisted Evaluation of Solvent Based- or Pressurized Hot Water Extraction for the Extraction of Artemisinin from Artemisia annua L. Processes 2017, 5, 86. [CrossRef]

45. Kornecki, M.; Strube, J. Accelerating Biologics Manufacturing by Upstream Process Modelling. Available online: https://www.mdpi.com/2227-9717/7/3/166 (accessed on 28 March 2019).

46. Michaels, A.S. New Separation Technique for CPI. Chem. Eng. Prog. 1968, 64, 31-43.

47. Wijmans, J.G.; Nakao, S.; Smolders, C.A. Flux limitation in ultrafiltration: Osmotic Pressure Model and Gel Layer Model. J. Membr. Sci. 1984, 20, 115-124. [CrossRef] 
48. Young, M.E.; Carroad, P.A.; Bell, R.L. Estimation of diffusion coefficients of proteins. Biotechnol. Bioeng. 1980, 22, 947-955. [CrossRef]

49. Binabaji, E.; Rao, S.; Zydney, A.L. The osmotic pressure of highly concentrated monoclonal antibody solutions: Effect of solution conditions. Biotechnol. Bioeng. 2014, 111, 529-536. [CrossRef] [PubMed]

50. Da Costa, A.R.; Fane, A.G.; Wiley, D.E. Spacer characterization and pressure drop modelling in spacer-filled channels for ultrafiltration. J. Membr. Sci. 1994, 87, 79-98. [CrossRef]

51. Saeed, A. Effect of Feed Channel Spacer Geometry on Hydrodynamics and Mass Transport in Membrane Modules. Ph.D. Thesis, Curtin University, Bentley, Australia, 2012.

52. Da Costa, A.R.; Fane, A.G.; Fell, C.J.D.; Franken, A.C.M. Optimal channel spacer design for ultrafiltration. J. Membr. Sci. 1991, 62, 275-291. [CrossRef]

53. Schmidt, A.; Richter, M.; Rudolph, F.; Strube, J. Integration of Aqueous Two-Phase Extraction as Cell Harvest and Capture Operation in the Manufacturing Process of Monoclonal Antibodies. Antibodies 2017, 6, 21. [CrossRef]

54. Gronemeyer, P.; Ditz, R.; Strube, J. Implementation of aqueous two-phase extraction combined with precipitation in a monoclonal antibody manufacturing process. Chim. Oggi/Chem. Today 2016, 34, 66-70.

(C) 2019 by the authors. Licensee MDPI, Basel, Switzerland. This article is an open access article distributed under the terms and conditions of the Creative Commons Attribution (CC BY) license (http://creativecommons.org/licenses/by/4.0/). 